adequate rate of rewarming following insulation. Active external rewarming using a hot bath, plumbed garments, hot water bottles, and heat pads and blankets applied to the trunk have been advocated in victims of immersion hypothermia with a palpable pulse. Active rewarming is usually required when the core temperature is below $32^{\circ} \mathrm{C}$. Cardiovascular collapse associated with sudden peripheral vasodilatation is a potential complication of these techniques, and careful monitoring is essential. Resuscitation is impossible in a hot water bath

Patients in cardiorespiratory arrest require rapid temperature elevation using active internal rewarming techniques. Options include peritoneal and pleural lavage ${ }^{16}$ heated humidified oxygen, ${ }^{17}$ and mediastinal irrigation and direct myocardial lavage. ${ }^{18}$ Intravenous fluids should be warmed; however, the risk of fluid overload precipitating pulmonary oedema limits their use as a means of rewarming. The use of Ringer's lactate solution should be avoided because hepatic metabolism of lactate is reduced in hypothermia. Administration of heated fluids through a central venous cannula can produce myocardial thermal gradients and precipitate arrhythmias.

Extracorporeal circulation is the treatment of choice in hypothermic cardiac arrest. ${ }^{12141519}$ The main advantage of rewarming by cardiopulmonary bypass is the preservation of blood flow to the brain and other vital organs and rapid core temperature elevation of $1-2^{\circ} \mathrm{C}$ every three to five minutes. However, cardiopulmonary bypass can only be performed by an experienced team and when the equipment is available. Consequently cardiopulmonary bypass in practice is usually instituted after other active internal rewarming methods have been started.

The longest reported conventional cardiopulmonary resuscitation in a hypothermic victim followed by survival is six hours $30 \mathrm{~min}$ utes. ${ }^{20}$ Although the aphorism "No one is dead until warm and dead" is generally applicable, rewarming to near normal core temperature is not practicable in every case. Rewarming efforts should probably be continued until the core temperature is at least $32^{\circ} \mathrm{C}$ and may be discontinued if the patient continues to show no effective cardiac rhythm and remains totally unresponsive to all treatments. ${ }^{12}$ However, the decision to terminate resuscitation must take into account the circumstances of each incident.

Resuscitation of the patient was achieved through a joint effort, and the participation of physicians, nurses, technicians, and members of the emergency services who assisted is gratefully acknowledged.

1 Hayward JS, Eckerson JD, Collis ML. Thermal balance and survival time prediction of man in cold water. Can J Physio survival time prediction of man

2 Reuler JB. Hypothermia: pathophysiology, clinical settings and management. Ann Intern Med 1978;89:519-27.

3 Nozaki $R$, Ishibashi $K$, Adachi $N$, Nishihara $S$, Adachi $S$. Accidental profound hypothermia. N Engl J Med 1986; 315:1680.

4 Lloyd EL. Hypothermia and cold. Sci Prog Oxf 1989;73: 101-16.

5 Webb P. After drop of body temperature during rewarming: an alternative explanation. J Appl Physiol 1986;60:385-90.

6 Southwick FS, Dalgleish PH. Recovery after prolonged asystolic cardiac arrest in profound hypothermia. JAMA 1980;243:1250-3.

7 Golden FStC. Problems of immersion. Br J Hosp Med 1980;24:371-4

8 Medical commission on accident prevention. Report of the working party on out of hospital management of hypotherworking party on out of hospital management of hypother-

9 Lloyd EL. Temperature and performance. 1. Cold. BMJ 1994;309:531-4.

10 Harries M. Near drowning: In: Colquhoun ML, Handley AJ, Evans JR, eds. $A B C$ of resuscitation. London: BMJ publishing group, 1995:50-3.

11 Steedman DJ. Environmental medical emergencies. Oxford Oxford University Press, 1994:1-25.

12 Weinberg AD. Hypothermia. Ann Emerg Med 1993;22 370-7.

13 Keatinge WR. Hypothermia: dead or alive? BMJ 1991;302:

14 Danzl DF, Pozos RS. Accidental hypothermia. N Engl J Med 1994;331:1756-60.

15 Larach MG. Accidental hypothermia. Lancet 1995;345: 493-8.

16 Otto RJ, Metzler MH. Rewarming from experimental hypothermia: comparison of heated aerosol inhalation peritoneal lavage and pleural lavage. Crit Care Med 1988; $16: 869-75$

17 Lloyd EL. Equipment for airway warming in the treatmen of accidental hypothermia. J Wilderness Med 1991;2:330 50.

18 Brunette DD, Biros M, Mlinek EJ, Erlandson C, Ruiz E. Internal cardiac massage and mediastinal irrigation in hypothermic cardiac arrest. Am J Emerg Med 1992;10: 32-4.

19 Walpoth BH, Locher T, Leupi F, Schupbach P, Muhlemann W, Althaus U. Accidental deep hypothermia with cardiopulmonary arrest: extracorporeal blood rewarming in 11 patients. Eur J Cardiothorac Surg 1990;4:390-3.

20 patients. Eur J Cardiothorac Surg 1990;4:390-3. Lexow $K$. Severe accidental hypothermia. survival after Med Res 1991;50(suppl 6):112-4.
Department of

Emergency Medicine,

St George Hospital,

Kogarah, NSW 2217, Australia

G J Hollis

Correspondence to:

Dr G J Hollis, Registrar,

Department of Emergency

Medicine.

Accepted for publication 6 February 1997

\title{
Sixth cranial nerve palsy following closed head injury in a child
}

\author{
Abstract \\ A five year old female had an isolated \\ abducens nerve palsy following closed \\ head injury. There was no associated skull \\ fracture, haematoma, or other cranial \\ nerve injury. The significance, frequency,
}

and differential diagnosis of traumatic sixth cranial nerve injury is discussed, particularly in paediatric patients. Management is symptomatic; occlusion with an eye pad may be used if diplopia is significant. In young children alternate 
day occlusion of each eye will help prevent amblyopia. Most cases improve within three months and many resolve by six months. Residual palsy at six months is likely to be permanent and surgical treatment may be needed.

(F Accid Emerg Med 1997;14:172-175)

Keywords: abducens nerve palsy; closed head injury; child

\section{Case report}

A five year old female presented to the emergency department at 0627 hours by ambulance following a motor vehicle accident. She was the front seat passenger. Her father was the driver and had fallen asleep at the wheel, colliding at $30-40 \mathrm{kph}$ with a stationary vehicle, causing major deformation to the front end of their car.

The child complained of generalised headache, anterior chest and abdominal pain, and anterior neck pain. On arrival she was haemodynamically stable and had chest and lower abdominal bruising in a "lap-sash" seat belt distribution. Also, minor bruising to the right temporal region was noted, thought to be caused by contact with her father's elbow or shoulder during the accident. There was no loss of consciousness at the scene or later. Her only past history was of mild asthma.

Radiology of cervical spine, chest, sternum, and pelvis was normal. Routine blood tests were also normal. Abdominal computerised tomography was also performed because of abdominal tenderness, and was normal. The child was admitted for observation.

During the next few hours she vomited twice and began to complain of diplopia. On re-examination she was found to have paralysis of lateral gaze of the left eye. Glasgow coma score remained 14 to 15 throughout (she was uncooperative at times). Neurosurgical consultation was obtained and urgent cerebral computerised tomography (non-contrast) was

Table 1 Causes of abduction deficits

\section{Sixth nerve palsies}

Graves myopathy (fibrotic medial rectus)

Myasthenia

Orbital inflammatory pseudotumour

Orbital trauma (medial rectus entrapment)

Congenital defects (Duane, Mobius)

"Convergence spasm"

From Duane's Clinical Ophthalmology. ${ }^{23}$

Table 2 Causes of abducens nerve palsy

\begin{tabular}{lll}
\hline & $\begin{array}{l}\text { Adults (and } \\
\text { combined) }\end{array}$ & Children \\
\hline Congenital & Rare & Rare \\
Trauma & $6-17 \%$ & $20-34 \%$ \\
$\begin{array}{l}\text { Neoplasia (meningioma, acoustic neuroma, nasopharyngeal } \\
\quad \text { carcinoma, others) }\end{array}$ & $8-15 \%$ & $27-39 \%$ \\
$\begin{array}{l}\text { Idiopathic } \\
\text { Inflammatory (arteritis, diabetes mellitus, cavernous sinus) }\end{array}$ & $21-30 \%$ & $9-15 \%$ \\
$\quad \begin{array}{l}\text { Vascular (including aneurysm, infarction, arteriovenous fistula, } \\
\quad \text { internal carotid dissection) }\end{array}$ & $18-37 \%$ & $0-3 \%$ \\
$\begin{array}{l}\text { Multiple sclerosis/demyelinating disorders } \\
\text { Lumbar puncture }\end{array}$ & $0-13 \%$ & - \\
$\quad \begin{array}{l}\text { Miscellaneous (pseudotumour, hydrocephalus, infection- } \\
\text { leptospirosis; basal meningitis, otitis media, others) }\end{array}$ & $0-4 \%$ & - \\
\hline
\end{tabular}

Compiled from various sources. ${ }^{45613}$ Not intended to be an exhaustive list. performed, which was normal. She had no other cranial nerve injury, either clinically or radiologically.

The following day, ophthalmology review was obtained and the ophthalmologist commented that he was unable to be certain whether the signs were due to pure sixth cranial nerve palsy, or to an associated injury in the region of the pons gaze centre.

She was observed in hospital, remained stable, and was transferred on day 3 for magnetic resonance imaging of the brain at the request of the neurosurgeon (for technical reasons the scan was done at a paediatric hospital). T1 and T2 views were obtained, including $3 \mathrm{~mm}$ sagittal slices through the brain stem. The scan was normal, and in particular there was no abnormality in the pons. No skull fracture was seen on either the magnetic resonance scan or the earlier computerised tomography. A paediatric neurologist also reviewed the patient at that hospital, agreed the diagnosis was abducens nerve palsy, and suggested an eye patch until ophthalmological follow up appointment.

The paralysis of lateral gaze persisted, and she was discharged on day 4 . At three months after the initial injury there had been significant improvement, but some weakness of lateral gaze persisted. She continues under ophthalmological review.

\section{Discussion}

This case was of interest since isolated sixth nerve palsy in the setting of trauma-while well documented-is not common, has not been recently reviewed, and is infrequently seen by the emergency physician. When seen it is often associated with other cranial nerve abnormalities, particularly of the third and fourth nerves, and with fracture or haematoma (see below). In this case, with normal cerebral computerised tomography, further investigation may have been unwarranted because of the low yield of positive results. Nevertheless, magnetic resonance imaging was also done to help eliminate other possible causes. While there are well recognised findings on magnetic resonance imaging for many of the causes of abducens nerve palsy, ${ }^{1}$ abnormal radiological findings in the setting of trauma are rare. ${ }^{2}$

The differential diagnosis of failure of lateral gaze is shown in table $1 .^{1}$ Of particular importance in the setting of head injury is facial fracture involving the medial wall of the orbit. This can cause entrapment of the medial rectus muscle and present as an apparent sixth nerve palsy. ${ }^{3}$ Most of the causes of sixth nerve palsy and their relative frequencies in various studies are shown in table $2 .^{2}$ Trauma and neoplasia are more common causes in children, and vascular causes are more common in adults.

Trauma is one of the more frequent causes of sixth cranial nerve injury, particularly in children, and although it can occur with skull fracture, haematoma, or raised intracranial pressure, it may have no associated features. ${ }^{3-5}$ 
The abducens nerve is particularly vulnerable to trauma because of its long intracranial course. It may be injured as it crosses the apex of the petrous part of the temporal bone. It may be stretched as it passes from the brainstem to its entry to the dura at the basilar process by downward and forward displacement of the brain stem. It may also be injured by fracture of the cranial floor, meningeal oedema, or inflammation in the skull base.

In the setting of closed head injury without fracture, haematoma, or raised intracranial pressure, it has been suggested that the most likely mechanism of injury is stretching of the nerve by acceleration in the mid-sagittal plane at the time of impact. The apex of the petrous bone acts as the fulcrum, so the abducens nerve is compressed, contused, and stretched at this point. ${ }^{367}$ It seems that this may occur in the absence of direct head trauma, as two cases of abducens nerve injury after cervical spine extension injury, or "whiplash", have been reported. One was unilateral, one bilateral, and neuroradiology was normal with good recovery of function in both cases. In the unilateral case, onset was not until five days after the incident. ${ }^{89}$

Bilateral abducens nerve palsy following trauma is a rare event, ${ }^{711}$ but several cases have been reported. There seem to be more reports of this injury without fracture or haematoma than with, but perhaps this is because those others are deemed less interesting and therefore not reported. Takagi et $a l^{12}$ reported three cases, none of whom had any neuroradiological abnormality (one case had angiography), and two had complete recovery of abducens nerve function over several months. Marconi et $a l^{11}$ discuss a case of bilateral palsy with skull fracture and intracranial haematoma that resolved completely after six months. Arias ${ }^{7}$ discusses a case of bilateral palsy with cervical spine fracture, but without skull fracture or intracranial haematoma, and refers to two previous similar cases. The mechanism is probably similar to the "whiplash" injuries discussed above.

When bilateral sixth nerve palsy occurs, it can indicate serious intracranial pathology, and after trauma raised intracranial pressure must be suspected until proven otherwise. However, as discussed above, there may be no abnormality on investigation, and the paresis can follow a benign course with full resolution. Cases of bilateral abducens palsy (one case) and unilateral palsy (several cases) have also been reported after lumbar puncture. ${ }^{14}$ Miller et $a l^{15}$ reported three cases of bilateral sixth nerve palsy following water soluble myelography. All three cases were benign and resolved spontaneously.

Several rare vascular causes of isolated sixth cranial nerve palsy have been described. Two reports were found of isolated sixth nerve palsy following spontaneous dissection of the internal carotid artery. ${ }^{1718}$ There were also two reports of intracavernous carotid aneurysm presenting as isolated unilateral abducens nerve palsy as the sole feature. ${ }^{1920}$ Morioka et $\mathrm{al}^{21}$ reported two cases of isolated bilateral sixth cranial nerve palsy following subarachnoid haemorrhage due to rupture of vertebral artery aneurysm. Both made full recovery within one year. Migraine has also been reported as a cause. ${ }^{22}$

The recommended management in traumatic uncomplicated sixth nerve palsy is monthly review by an ophthalmologist for six months. Most cases improve within three months and many resolve by six months. ${ }^{5}$ Management during this period is symptomatic; occlusion with eye pad may be used if diplopia is significant. In young children alternate day occlusion of each eye will help prevent amblyopia. Residual palsy at six months is likely to be permanent. ${ }^{16}$ Surgery may be considered at this stage, and involves either muscle transfer of the vertical recti insertions, or permanent joining of the vertical and lateral recti, with or without lateral rectus resection. The aim is to increase resistance to the pull of the normal medial rectus and reduce diplopia. ${ }^{16}$

\section{CONCLUSION}

Isolated sixth nerve palsy following trauma is not uncommon, particularly in children. The important differential diagnoses should be considered as discussed above, and it is especially important not to miss facial fracture with medial rectus muscle entrapment. Once serious intracranial injury or raised intracranial pressure is excluded clinically and (if indicated) radiologically, the patient may be managed with the normal protocol for a head or neck injury. Ophthalmological referral and follow up should be arranged.

1 Depper MH, Truwitt CL, Dreisbach JN, Kelly WM. Isolated abducens nerve palsy: MR imaging findings. Am J Roentgenol 1993;160:837-41.

2 Berlit P, Reinhardt-Eckstein J, Krause KH. Isolated abducens paralysis-a retrospective study of 165 patients. abducens paralysis-a retrospective study of

3 Hipwell G. The differential diagnosis of diplopia. Modern Medicine of Australia 1992;Oct:141.

4 Moster ML, Savino PJ, Sergott RL, Bosley TH, Schatz NJ. Isolated sixth nerve paresis in younger adults. Arch Ophthalmol 1984;102:1328-30.

5 Robertson DM, Hines DJ, Rucker CW. Acquired sixth nerve paresis in children. Arch Ophthalmol 1970;83: 574-5.

6 Rush JA, Younge BR. Paralysis of cranial nerves III, IV, and VI, cause and prognosis in 1000 cases. Arch Ophthalmol 1981;99:76-9.

7 Arias MJ. Bilateral traumatic abducens nerve palsy without skull fracture and with cervical spine fracture. Neurosurskull fracture and with

8 Yamashita K, Kobayashi S, Oguro H, Yamaguchi S. A case of abducens nerve palsy after whiplash injury. No To of abducens nerve pals

9 Shifrin LZ. Bilateral abducens nerve palsy after cervical spine extension injury - a case report. Spine 1991;16: 374-5.

10 Limnaios EE, Papageorgiou CT. Bilateral Abducens nerve palsy. Ophthalmologica 1980;181:326-9.

11 Marconi F, Parenti G, Dobran M. Bilateral traumatic abducens nerve palsy—a case report. J Neurosurg Sci 1994;38: 177-80.

12 Takagi H, Miyasaka Y, Kuramae T, Ohwada T, Tsunoda M Bilateral traumatic abducens nerve palsy without skull racture or intracranial haematoma- a report of three cases Geka 1976;4:963-9.

13 Harley RD. Paralytic strabismus in children. Ophthalmology 1980;87:24-43.

14 Insel TR, Kalin NH, Risch SC, et al. Abducens palsy after lumbar puncture [letter]. N Engl J Med 1980;303:703.

15 Miller EA, Savino PJ, Schatz NJ. Bilateral sixth nerve palsy, a rare complication of water-soluble contrast myelography. Arch Ophthalmol 1982;100:603-4. 
16 Parks MM, Mitchell PR. Cranial nerve palsies. In: Tasman W, Jaegar EA, eds. Duane's clinical ophthalmology. Philadelphia: JB Lippincott, 1994;1(19):12-17.

17 Maitland CG, Black IL, Smith WA. Abducens nerve palsy due to spontaneous dissection of the internal carotid artery. Arch Neurol 1983;40:448-9.

18 Lal V, Sawhney IM, Bansal SK, Prabhakar S. Abducens nerve palsy due to spontaneous internal carotid artery nerve palsy due to spontaneous internal carotid artery
dissection-a case report. Comput Med Imaging Graphics 1994;18:381-3.

19 O'Dell KB, Gordon RS. Intracavernous carotid aneurysm - an unusual cause of isolated abducens nerve palsy. Ann Emerg Med 1990;19:1063-5.
20 Stracciari A, Ciucci G, Bianchedi G, Rebucci GG. Isolated sixth nerve palsy due to intracavernous carotid aneurysm in a young woman. Acta Neurol Belg 1988;88:148-51.

21 Morioka T, Matsushima T, Yokoyama N, Muratani H, Fugii $\mathrm{K}$, Fukui $\mathrm{M}$. Isolated bilateral abducens nerve palsies caused by rupture of a vertebral artery aneurysm. Clin Ophthalmol 1992;12:263-7.

22 De Renzi E, Nichelli P. Ophthalmoplegic migraine with persistent abducens nerve palsy. Eur Neurol 1977;15:227-30.

23 Glaster JS. Infranuclear disorders of eye movement. In: Tasman W, Jaegar EA, eds. Duane's clinical ophthalmology. Philadelphia: JB Lippincott, 1994;2(12):3-9.

\title{
Pharyngeal coin removal in children
}

\author{
S M Mason
}

\begin{abstract}
Two cases of coin extraction from the upper third of the oesophagus are described, using a Foley catheter in the accident and emergency department without complication. Although previously reported, the method is not widely used; indeed many junior doctors appear unaware of it. Coins can be removed from this proximal position provided the operator is confident and swift. This appears to be a safe and useful technique, avoiding the need for hospital admission and anaesthesia. It is worth trying before resorting to endoscopy.

$(\Im$ Accid Emerg Med 1997;14:175-176)
\end{abstract}

Keywords: Foley catheter; oesophagus; impacted coin

This is a review of a method of oesophageal coin removal that is a cheap, convenient, and quick way of removing coins lodged in the upper oesophagus. Children commonly ingest foreign bodies, most of which enter the stomach and pass through the digestive system without any complications. Occasionally they become lodged in the oesophagus and require removal to prevent complications. There are three main points at which a coin can lodge: the cricopharyngeus, the level of the aortic arch, and the gastro-oesophageal junction. This article presents two reports of children with coins lodged at the level of cricopharyngeus, and their subsequent management.

\section{Accident and \\ Emergency \\ Department, Northern \\ General Hospital, \\ Herries Road, \\ Sheffield S5 7AU \\ S M Mason \\ Correspondence to: Suzanne Mason, Research Fellow in Accident and Emergency Medicine.

\section{Case reports}

On separate occasions, a girl aged 18 months and a two year old boy each attended the accident and emergency department with a history of having swallowed a coin while playing. Since ingestion, although undistressed, both children repeatedly vomited when they tried to take any food or fluids. A chest $x$ ray revealed the coins lodged at the cricopharyngeal level in the upper oesophagus. Discussion with the childrens' parents outlined the options for removal, and a decision was made to try and remove the coin in the accident and emergency department. The following technique was successfully used in both children.

\section{The technique}

The procedure should be performed in a calm setting with the child attached to a pulse oximeter with suction and intubation equipment close at hand. We also advocate the presence of a clinician in the department familiar with paediatric airway management who would be available to deal with any untoward complications. No sedation is required, just a little encouragement. The child should be wrapped in a blanket to reduce movement and held sitting upright. A size 14 Foley catheter is fed into the child's mouth in a positive fashion, while encouraging the child to swallow and using each swallow to advance the catheter further. Once the catheter has been introduced up to the hilt and care has been taken to ensure it is not coiled in the back of the mouth, the balloon can be inflated with up to $10 \mathrm{ml}$ of air and gentle traction on the catheter begun while tilting the child slightly forwards. The first attempt to dislodge the coin may be unsuccessful, but children will tolerate a repeat procedure and the coin should be ejected out of the mouth ahead of the catheter. The child should remain in the department until fully recovered and tolerating fluids. They may then be allowed home with instructions to return should any problems arise. It should be noted that some children will not tolerate the procedure at all and alternative methods should be employed in this situation.

\section{Discussion}

Coins lodged in the upper two thirds of the oesophagus are unlikely to pass spontaneously into the stomach and therefore require a safe method of removal. ${ }^{1}$ If left in situ, complications may develop after 24 hours, with mucosal inflammation initially causing localised swelling and later leading to tissue necrosis and longer term complications. Previous reports have described respiratory complications from local obstruction due to external pressure. ${ }^{2}$ In 